\title{
Dr. Jyotsna Murthy: A Life Well Lived
}

\author{
Syed Altaf Hussain ${ }^{1}$
}

${ }^{1}$ The Cleft \& Craniofacial Centre, Department of Plastic Surgery, SRMC Hospital, Sri Ramachandra Institute of Higher Education and Research, Chennai, Tamil Nadu, India

Indian J Plast Surg 2020;53:12-14

"A life well lived is long enough"

-Lucius Annaeus Seneca, first century AD

Dr. Jyotsna Murthy often just known as Jyotsna was born Jyotsna Patel in a business family in Anand, Gujarat. She did her MBBS from Baroda and her MS General surgery from the Tata Memorial Hospital, Mumbai. Following this, she joined MCh, Plastic Surgery program at the Sion Hospital, Mumbai. After completing her training in Plastic Surgery, she worked in Paris for 4 years before returning to India in 1994. She did a short stint as a research officer at the Stanley Hospital, Chennai, and subsequently moved to Sri Ramachandra Medical College Hospital as Assistant Professor and went on to become a Professor of Plastic Surgery. She also acquired her $\mathrm{PhD}$ in the genetics of cleft during this period. In addition to being very capable and compassionate surgeon, she was a great human being and was held in the highest esteem by her patients, colleagues, peers, and friends. ( - Fig. 1).

During her training at the Sion hospital under Professor Ravin Thatte, she was exposed to a large variety of cases. Alongside her colleagues, Dr. Nitin Mokal and Dr. Mukund Thatte, she learnt to deal with complex problems in innovative ways. She focused very early on positioning herself as a pediatric plastic surgeon and worked systematically toward it. This was at a time when most plastic surgeons were worried that subspecialization in plastic surgery would restrict their practice.

Jyotsna took every opportunity to learn from the best surgeons in the world. While working in Paris, she learnt from Dr. Rene' Malek, his modification of Petit's pharyngoplasty. She visited Dr. Sam Noordhoff in Taipei (-Fig. 2) and learnt his refinements in the repair of unilateral cleft lip. She also forged a bond of friendship with him that lasted their lifetimes. Such was her commitment to mastering the technique that she would read his monograph on cleft lip repair every day before undertaking the operation. Similarly, she learnt the nuances of bilateral cleft lip from Dr. John Mulliken in Boston (-Fig. 3), as well as aspects of palate repair from Dr. H.S. Adenwalla in Thrissur. She also visited cleft centers across the world and hosted several top cleft surgeons in Chennai to learn their best practices first-hand.

DOI https://doi.org/

10.1055/s-0040-1709813 ISSN 0970-0358.
Address for correspondence Syed Altaf Hussain, MS, FRCS, DNB, The Cleft \& Craniofacial Centre, Department of Plastic Surgery, SRMC Hospital, Sri Ramachandra Institute of Higher Education and Research, Porur, Chennai 600116, Tamil Nadu, India (e-mail: sa_hussain@hotmail.com).

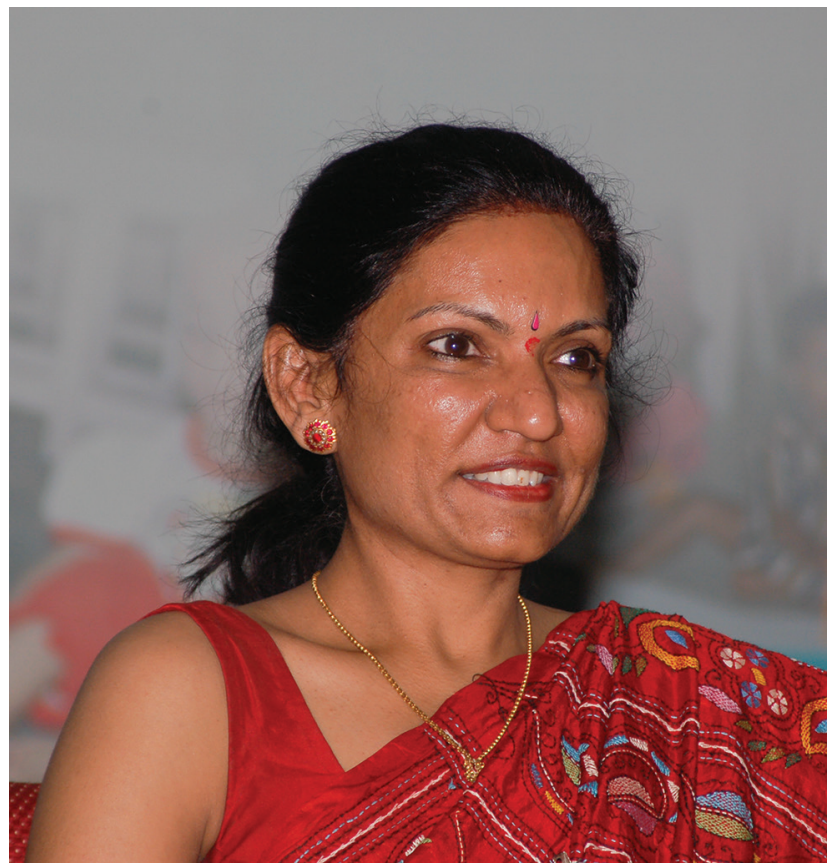

Fig. 1 Dr. Jyotsna Murthy, MS, MCh, DNB, PhD (1962-2020).

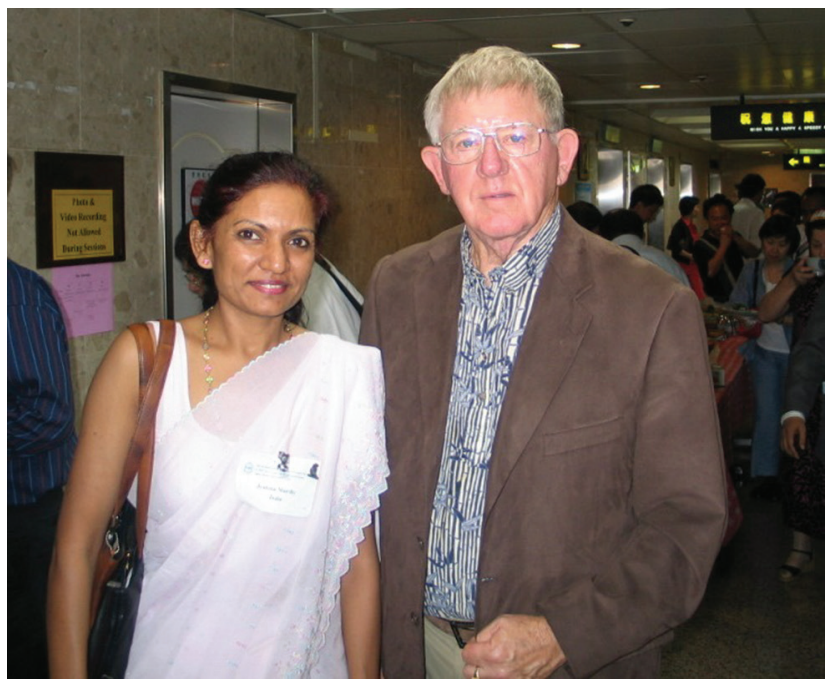

Fig. 2 Dr. Jyotsna Murthy with Dr. Sam Noordhoff in Taipei.

(C)2020 Association of Plastic Surgeons of India
License terms

(요 (1) $\odot \circledast$ 


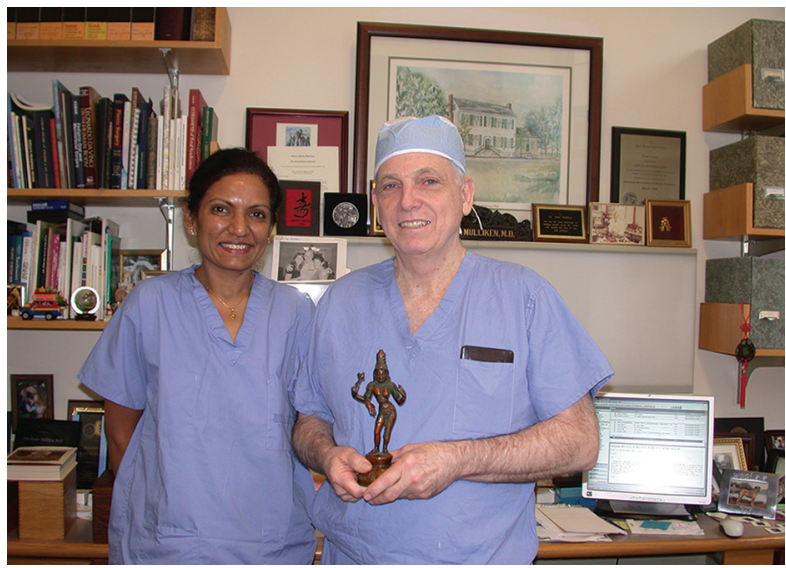

Fig. 3 Dr. Jyotsna Murthy with Dr. John Mulliken in Boston.

At the turn of the millennium, a newly formed Smile Train India, which was headed by Mr. Satish Kalra, was looking to support cleft care in India. The Charles Pinto Centre at Trichur was the first to be chosen as a partner. This was followed by the cleft and craniofacial center at Sri Ramachandra Medical College Hospital (SRMC), Chennai (-Fig. 4). This came about because Jyotsna, though a relative newcomer to cleft care at that time, was able to convince Smile Train's medical advisor Dr. Sam Noordhoff of her commitment to the cause. His confidence was not misplaced, and the center went on to be counted among the best centers anywhere in the world. Though the initial funding was only for surgery, she could expand the service to a full-fledged multidisciplinary care by appealing to the need of each of the departments to register a critical number patients in their respective specialties to comply with the requirements of the university. She chose her colleagues with great care, involved them actively in multidisciplinary cleft care, and treated them as equal partners.

Perhaps her most admirable characteristic was an open mind and the ability to learn from her mistakes and others. She would even learn from those much junior to her. I have seen her radically change her technique more than once when she was convinced that a different one could yield slightly better results. She had unlimited energy and would not hesitate to start a new unscheduled case at the end of a long list if needed.

Jyotsna constantly strived to improve further her surgical techniques which she had perfected by incorporating several techniques she had picked up from the different parts of the world. She audited her results of lip repair for several years and found that the rotation advancement technique, which she had been practicing for most of her working life, was causing unacceptable scars in our population, as it was violating natural landmarks in the lip. Hence, she changed her technique to straight-line repair which she found was more suitable for our population. Similarly, she found that the vermillion transfer popularized by Sam Noordhoff which she had been practicing for several years, was cutting across the tubercle of the lip and distorting its contour. Subsequently, she modified her technique to preserve the tubercle. ${ }^{1}$

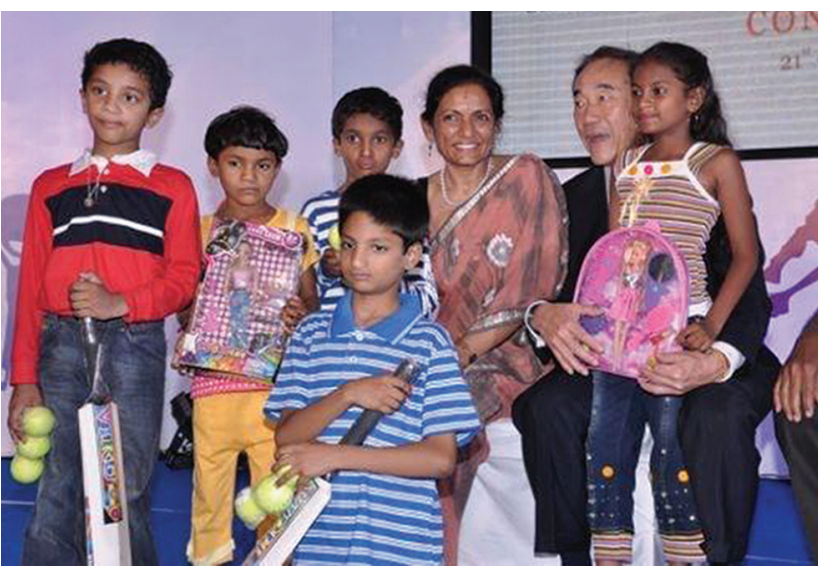

Fig. 4 Dr. Jyotsna Murthy with The Late Charles Wang, founder of Smile Train in Chennai.

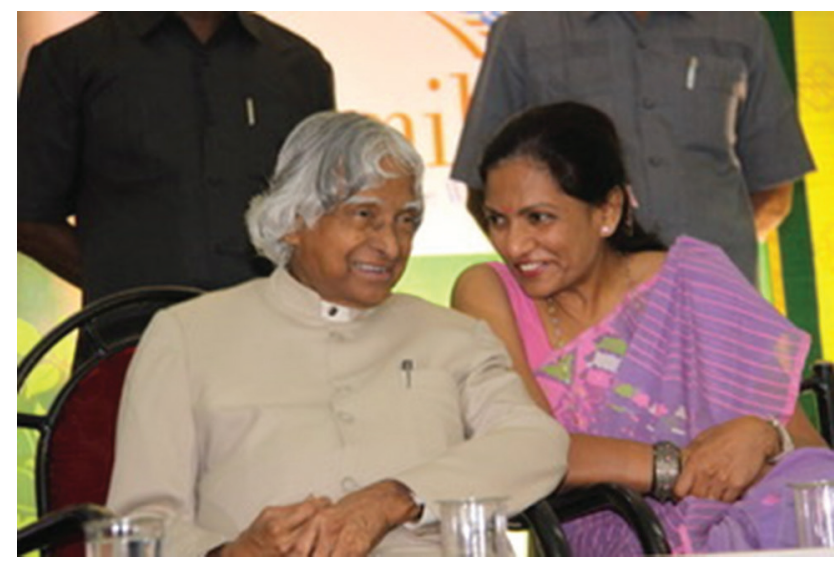

Fig. 5 Dr. Jyotsna Murthy with the Late President of India Dr. Abdul Kalam.

Dr. Jyotsna prided herself as a meticulous surgeon. She insisted that speed came from having planned and rehearsed the steps of the operation several times in her mind beforehand, and not by hurrying or cutting corners. She would also not shy away from taking up the most difficult cases.

Jyotsna, as we well know, was a skillful surgeon, a great organizer, and a very gritty woman who dealt with the greatest of personal adversities with absolute courage (-Fig. 5). She was, above all, a very good human being. There are a few things about her which stood out which only some of us knew. First and foremost was her deep empathy with the patients. She opened our eyes to what patients go through in the hospital and made sure that we would not make the patient undergo anything which we would not like for ourselves or someone close us, be it treatment, expenses, waiting, or unnecessary visits to the hospital. She continuously worked toward identifying patients as early as possible, particularly in villages and trying to secure appropriate funding to ease their treatment as much as she could (-Fig. 6).

She counted the entire who's-who of cleft and craniofacial care across the world among her friends. She frequently corresponded with most of them all her working life ( -Fig. 7). She was closely involved with the Association 


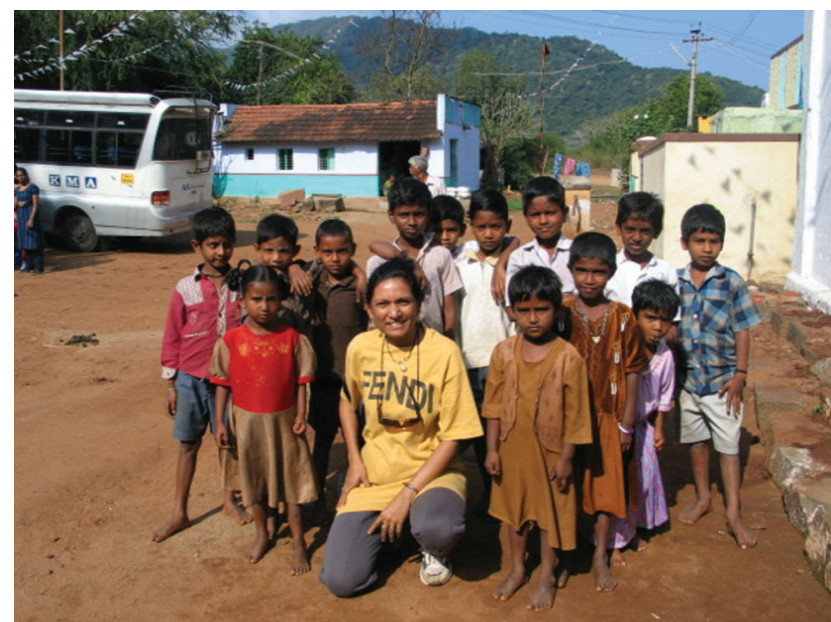

Fig. 6 Dr. Jyotsna Murthy at an outreach camp in rural Tamil Nadu.

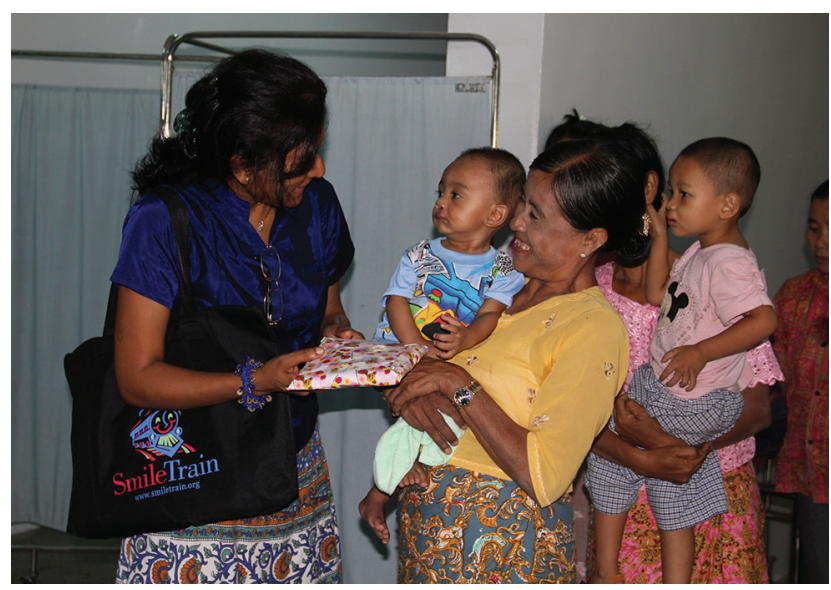

Fig. 7 Dr. Jyotsna Murthy with patients and family in Yangon, Myanmar.

of Plastic Surgeons of India (APSI) and Indian Society of Cleft Lip, Palate And Craniofacial Anomalies (ISCLP \& CA). She was involved in the founding and running of the latter and served as its Secretary and later President. She played a pivotal role in India's successful bid for the International Cleft and Craniofacial Congress and later served as its President in 2017.

Jyotsna was acutely aware of the environmental costs of unbridled consumption and depletion of resources caused by human greed. She was against any wastage and prided herself in being frugal. She grew most of her own organic vegetables on her terrace garden and maintained an apiary for producing honey. She even invested in a solar cooker that she used to cook her lunch. Even in tropical Chennai, where air-conditioners are found even in shanties, she had none in her newly built house since she believed that air-conditioning contributed to global warming. This extended to her professional life and was a great believer in not wasting any resources in the operating room and in the hospital.

Like everything else that she took on, she fought a spirited battle against cancer. I have found her operating shortly after having undergone a major surgery with a drain still attached. On more than one occasion, she had chemotherapy in the morning and continued her work in the afternoon.

Jyotsna, surgeon par excellence, a compassionate human, an esteemed colleague and valued friend passed away in the early hours of February 16, 2020 at the Isha Yoga Center in Coimbatore in Tamil Nadu where she found solace in the later years of her short life. She continues to live in the memories of her family, friends, patients, colleagues, trainees, and peers spread across the world whose lives she had touched and enriched. She leaves behind the enduring legacy of a cleft and craniofacial service which provides world-class multidisciplinary care, no matter the socioeconomic state of the patient.

\section{References}

1 Murthy J. The refinement of the median tubercle of cleft lip. Indian J Plast Surg 2018;51(2):131-136 